\title{
POLÍTICAS EDUCACIONAIS PARA ATENDIMENTO À DIVERSIDADE NA EDUCAÇÃO SUPERIOR NA AMÉRICA LATINA: o caso brasileiro.
}

\author{
POLÍTICAS EDUCACIONALES DE ATENCIÓN A LA DIVERSIDAD EN \\ LA ENSEÑANZA SUPERIOR EN LATINOAMÉRICA: el caso brasileño
}

\section{EDUCATIONAL POLICIES FOR ATTENTION TO DIVERSITY IN HIGHER EDUCATION IN LATIN AMERICA: the brazilian case.}

Jose Wilson Rodrigues de Melo ${ }^{1}$

\begin{abstract}
Resumo
A América Latina é considerada a "Pátria da diversidade". No contexto da mundialização as perspectivas para incentivar o local estão sendo delineadas em meio a paradoxos e contradições. O objetivo do artigo que foi o de destacar a atenção à diversidade no ensino superior público federal brasileiro com vista às políticas de acesso e permanência dos estudantes. O problema estudado verificou o alcance das políticas públicas educacionais para atender a diversidade no ensino superior. Para dar conta da problemática foi recortada uma análise da efetivação do direito à educação superior em contraste com as ações do poder público. A metodologia utilizada procurou levantar artigos em "motores de busca" da internet. Foram utilizadas a base de dados ERIC, o "google scholar", o Portal de Periódicos da CAPES, o Scielo Brasil. Por último foi consultada a biblioteca do autor. Assim, foi obtido um resultado geral de 60 textos. Tendo o foco temático a partir dos descritores da pesquisa foi descartada uma gama considerável dos textos. Ao final, ficou observado um avanço nas políticas educacionais para atender à diversidade no ensino superior público federal brasileiro nos últimos anos. Entretanto, exclusões do diferente permanecem. Isto devido ao alcance limitado das políticas de acesso e permanência no ensino superior. Assim, a educação perde parte do seu papel na democratização da sociedade. A complexidade da relação da educação com as culturas, a sociedade e o Estado segue diante da resistência a processos globalizantes como mecanismos de exclusão e desrespeito à dignidade humana.
\end{abstract}

Palavras-chave: Brasil; Desigualdades Sociais; Diversidade; Educação Superior; Políticas Educacionais.

\section{Resumen}

América Latina es considerada la "Patria de la diversidad". En el contexto de la globalización las perspectivas para buscar acciones locales están siendo delineadas en medio a paradojas y contradicciones. El objetivo de este artículo es destacar la atención a la diversidad en la educación pública federal brasileña con vista a las políticas de acceso y permanencia de estudiantes en la educación superior. El problema estudiado encontró el alcance de las políticas educativas para satisfacer la diversidad en la educación superior. Para tener en cuenta el problema ha surgido una análisis de la realización del derecho a la educación superior, en contraste con las acciones del poder público, teniendo en cuenta la diversidad. La metodología ha procurado elegir artículos en "motores de búsqueda" de Internet. Fueran utilizadas la base de datos ERIC, el Portal de Periódicos da CAPES, el Scielo Brasil y Google scholar. Fue consultada la biblioteca del autor. Así, fue obtenido un resultado general de 60 textos. Con el enfoque temático a partir de los descriptores de la investigación fue descartada una gama de textos. Al final, la investigación observó una mejora en las políticas educativas para la diversidad en la educación superior pública federal brasileños. Sin embargo, exclusiones permanecen por el alcance limitado de las políticas de acceso y permanencia en la educación superior. La complejidad de la relación de la educación, la cultura, la sociedad y el estado sigue en la resistencia a los procesos de globalización

Palabras-clave: Brasil; Enseñanza superior; Desigualdades Sociales; Diversidad; Políticas educacionales.

${ }^{1}$ (Doutor em Ciências da Educação; Universidade Federal do Tocantins - UFT; Palmas, Tocantins, Brasil; jwilsonrm@uft.edu.br). 


\begin{abstract}
Latin America is considered the "Homeland of diversity". In the context of globalization the prospects for encouraging the local are being drawn in the midst of paradoxes and contradictions. The objective of the article is to highlight the attention to diversity in Brazilian federal public higher education throw access and permanency of ethnic cultural students diversity. The problem studied verified the reach of educational public policies to attend diversity in higher education. In order to deal with the problem, a perspective of analysis of the effectiveness of the right to higher education was cut against the actions of the public power, taking into account diversity. The methodology sought to raise articles in "search engines" of the internet such as: ERIC database, "google scholar", Portal de periódicos da CAPES and Scielo Brasil. Lastly, queries from the author's library were used. Thus, a general result of 60 texts was obtained. Having the thematic focus from the search descriptors has discarded a range of texts. At the end, it was observed an advance in the educational policies to attend the diversity in the Brazilian public higher education in the last years. However, exclusions of the different remain. This is due to the limited scope of access and retention policies in higher education. Thus, education loses part of its role in the democratization of society. The complexity of the relationship between education and culture, society and the state continues to face resistance to global processes as mechanisms of exclusion and disrespect for human dignity.
\end{abstract}

Key words: Brazil; Diversity; Educational Policies; Higher Education; Social Inequalities.

\title{
1 INTRODUÇÃO.
}

A América Latina é considerada a "Pátria da diversidade" de acordo com o renomado jornalista Eduardo Galeanoi. No contexto da mundialização as perspectivas para incentivar o local estão sendo delineadas em meio a paradoxos e contradições (ORTIZ, 2004, p.25).

A perspectiva histórica fundacional das sociedades na América Latina - A. L. foi à de transplantação dos modelos de Estado, sociedade e cultura. O projeto colonizador trazia a ideia de implantar organizações societais referenciadas em alhures. Contudo, a diversidade cultural deveria ser assimilada ou, quiçá, dizimada. (QUIJANO, 2009, p. 210).

Transformações foram observadas quando dos processos independentistas e da instalação dos Estados-nacionais. A perspectiva no tratamento com a(s) cultura(s) foi a da homogeneização em torno dos estatutos linguísticos e demais elementos simbólicos na perspectiva dominante dos grupos detentores do controle da sociedade. De acordo com o pensamento de Renato Ortiz a diversidade cultural "es diferente y desigual porque las instancias y las instituciones que la construyen tienen distintas posiciones de poder y de legitimidad (... [países] transnacionales y gobiernos nacionales, civilización “occidental” o mundo islámico, Estado nacional o grupos indígenas)."

Suplantadas essas grandes fases chega-se ao contexto atual onde a atenção à diversidade adquire outro formato. A perspectiva é a da inclusão da diferença. A educação, dentro do projeto globalizante, toma um discurso de que a oferta seja para todos/as. A diferença é tida como bem-vinda ao projeto educacional e social. 
Nesta direção, sociedades multiculturais latino-americanas abraçaram a possibilidade de inclusão da diversidade na educação superior através de políticas de ação afirmativas. $O$ Brasil atende a este apelo com vigor. A inclusão da diversidade pôs-se como uma estratégia para acelerar o processo democratizante do acesso e da permanência no ensino superior.

É deste movimento em torno da expansão do acesso e da permanência no ensino superior que foi recortado o objeto de estudo do presente artigo. A ideia foi compreender a educação como um direito subjetivo. Enquanto direito social, o processo educacional conferido aos sujeitos de direito brasileiros necessita de políticas públicas para a efetivação de tal direito.

O pressuposto inicial é o de que as universidades são agências para ampliar o conhecimento científico e tecnológico, além do desenvolvimento humano. Deste modo são indispensáveis políticas públicas para o ensino superior.

O problema posto ao objeto em estudo foi o da efetividade das políticas públicas de acesso e permanência no ensino superior. Isto implica tanto em um processo de democratização da universidade quanto da sociedade.

O objetivo do artigo que foi o de destacar a atenção à diversidade no ensino superior público federal brasileiro com vista às políticas de acesso e permanência dos estudantes com expressões marcadas pela diversidade étnico-cultural. O problema estudado verificou o alcance das políticas públicas educacionais para atender à diversidade no ensino superior. Para dar conta da problemática foi recortada uma perspectiva de análise da efetivação do direito à educação superior em contraste com as ações do poder público levando-se em consideração a diversidade.

A metodologia utilizada procurou levantar artigos em "motores de busca" da internet. Em um primeiro momento foi utilizada a base de dados ERIC. Em seguida foi utilizado o "google scholar". Foram realizadas ainda buscas no Portal de Periódicos da CAPES. Depois foram procurados artigos no Scielo Brasil. Em seguida foi utilizado o "Google scholar". Por último foram realizadas consultas na biblioteca do próprio autor. Assim, foi obtido um resultado geral de 60 textos. Tendo o foco temático a partir dos descritores da pesquisa foi descartada uma gama considerável dos textos.

O texto está organizado em três secções integradas e complementares. A tessitura entre as mesmas atende ao diálogo entre os descritores principais para o estabelecimento das discussões em torno do objeto de análise. Na configuração do todo articulado buscou-se uma dialogicidade com elementos representativos da formação histórica, social e cultural da A.L. Este recorte foi procurado para situar a dinâmica das políticas de acesso e permanência à 
educação superior no Brasil em consonância com o continente. Isto porque a A.L. é vista como a "pátria da diversidade", mas também o paraíso das desigualdades. Assim, a primeira secção do texto foi intitulada <<Da relação estado, sociedade, cultura e educação $>$. A seguinte: <<Da realidade da educação superior brasileira às desigualdades na efetivação dos direitos〉>. Por último: <<As políticas educacionais para atendimento à diversidade nas IFES nos últimos anos $>$.

\section{DA RELAÇÃO ESTADO, SOCIEDADE, CULTURA E EDUCAÇÃO.}

Como pressuposto impõe-se a evidente complexidade da formação das sociedades na A. L. Recortando-se para o caso brasileiro analogia equivalente pode ser realizada. O longo período colonial condensou marcas com repercussões estruturais duradouras. Vários aspectos podem ser tomados, mas para ficar no recorte do objeto de interesse neste artigo optou-se pela vertente étnica e cultural. Isto porque foi condensado um cadinho linguístico e cultural no desenvolvimento da história social do país.

A língua é o elemento fundacional de uma cultura. Todo o espectro abrangente e complexo desta está na formação de uma nação. A nação é o retrato da alma de um povo se for eleita uma alusão metafórica. Neste âmbito valores, sentimentos, crenças, costumes vão compor um amálgama centralizado na edificação de identidades. (ORTIZ, 1987, p.137).

Na A.L. e no Brasil por decorrência, a implantação do Estado ${ }^{i i}$ foi postiça. Equivale a dizer este resultado como produto de uma transladação oceânica. Em caravelas trouxeram um ordenamento de costumes, leis e regras. É patente constatar a função das leis como a de estabelecer controle diante dos indivíduos. Este controle é realizado em consonância com os princípios de uma dada sociedade.

Considerados estes pressupostos pode-se aventar que a composição dos Estados latinoamericanos decorreu mediante um longo e dolente "estupro cultural". iii As línguas da tradição ibérica foram impostas. As alteridades foram distorcidas. Assim, composições societais tão diversas foram submetidas a processos homogeneizantes ${ }^{\mathrm{iv}}$ e deletérios à diversidade. ${ }^{\mathrm{v}}$

Esta condição primeira de submissão cultural foi mantida quando da instituição dos Estados-nacionais. Na A. L. a formação destes entes jurídicos de direito público foi estabelecida, em geral, por descendentes culturais dos colonizadores. Assim, as leis e regras foram escritas com base nos costumes transplantados. Embora, estes resultados sejam implementados mediantes ajustes e aclimatação aos ambientes culturais em disputa. Ou seja, a nova ordem não consta de uma transplantação direta, mas de uma adaptação a um novo meio 
ambiente <<simbólico〉> (GEERTZ, 1989) ${ }^{\mathrm{vi}}$. Algo semelhante a um prato requentado. Deste modo, os movimentos nacionais, neste âmbito, foram delineados pela dissolução das diferenças. A homogeneização cultural ${ }^{\text {vii }}$ fez-se regra. Esta diretriz adquiriu força com a implantação dos sistemas nacionais de educação (DURKHEIM, 1973). Foi a educação (SAVIANI, 2008) a edificadora da Pátria. Foi na escola que os símbolos da nação e a língua encontraram forte guarida. Assim, a educação escolar consubstanciou-se como correia de transmissão da cultura enquanto cânone dos valores morais da nacionalidade.

$\mathrm{Na}$ contemporaneidade (BAUMAN, 2013) estes processos mais uma vez sofreram reveses. Os Estados-nacionais perderam força mediante os processos da globalização (BECK,

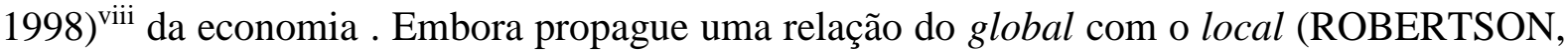
2000) esta perspectiva também se desenvolve como um projeto homogeneizante. A denominada quebra das fronteiras pode ser entendida como um neocolonialismo. Neste âmbito a diferença cultural é posta como mercadoria. $\mathrm{O}$ diferente cultural ${ }^{\mathrm{ix}}$ recebe uma espécie de convite para participar de um banquete, mas ele/ela o faz na condição de serviçal na posta da mesa. Enfim, é uma inclusão excludente.

A realidade social de um país pode ser verificada pelos índices de desigualdade social. Indicadores do Programa das Nações Unidas para Desenvolvimento - PNUD demonstram haver uma diminuição nos números gerais do Brasil entre os anos de 2006 e 2013. Os registros indicam uma variação entre 4,0 e 2,9\%. Para um país com séries históricas tão desfavoráveis esses resultados foram animadores. Contudo, ao utilizar uma metodologia diferenciada no cálculo do Desenvolvimento Humano - O IDH - D (Índice de Desenvolvimento Humano menos Desigualdade) a tendência acumulada no país ainda é desafiante. Descontada a desigualdade, o IDH teria uma perda de $26,3 \%$. A redução em razão da desigualdade situa esta realidade entre as maiores do grupo de países de Alto Desenvolvimento Humano (19,4\%), ficando atrás apenas do Irã $(33,6 \%)$ nessa categoria e à frente da média mundial $(22,8 \%)$.

As desigualdades passam por efeito paradoxal no contexto contemporâneo. Em alguns aspectos mais gerais apresentaram considerável diminuição, em outros, foram ampliadas. Especialistas destacam este movimento não ser apenas decorrente da globalização. Contudo, afirmam o mesmo está presente no centro da social cotidiana e das tensões particulares desta. As desigualdades precisam ser situadas nas experiências dos atores ou de alguns deles para daí serem extraídas conclusões de âmbito mais sociológico. Em grande parte das sociedades ocidentais foi criada uma espécie de fronteira opondo integrado e excluídos. Embora não haja uma demarcação delimitada e vários indivíduos circulem entre os diferentes territórios é 
notório o fenômeno da "latino americanização" com o crescimento da pobreza, da incerteza e da economia informa. (DUBET, 2010).

Isto posto, pode-se aferir uma imbricação bem cerzida entre o Estado, a sociedade, a cultura e a educação na constituição das realidades sociais dos países. Para o propósito deste estudo fica postulado a atenção á diversidade ainda como um fator a avançar. A diferença permanece com um tratamento centralizador no estabelecimento de desigualdades.

\section{DA REALIDADE DA EDUCAÇÃO SUPERIOR BRASILEIRA ÀS DESIGUALDADES NA EFETIVAÇÃO DOS DIREITOS.}

Dado aos acúmulos históricos das sociedades latino-americanas, o substrato dos sistemas nacionais de educação postou-se no estabelecimento de dualismos ${ }^{\mathrm{x}}$. Estes resultaram na edificação adensada das desigualdades.

A educação brasileira tem se desenvolvido a partir das diferentes etapas da formação do país. Para os recortes aqui indispensáveis pode ser tomado o período de implantação do sistema nacional de educação nos anos de 1930. Nesta época foi criado o Ministério dos Negócios da Educação e da Saúde. A Reforma Francisco Campos teve um protagonismo pioneiro no estabelecimento de regramentos delineados nas diretrizes e bases da educação. $\mathrm{O}$ Movimento dos Pioneiros da Educação Nova de 1932 trouxe um conjunto de princípios norteadores ensejando o rumo dos ventos da educação no país. Embora o <<Manifesto >> fale em uma educação para todos, o contrário fez-se realidade. A educação pública de qualidade, neste contexto, foi para poucos/as.

Em artigo intitulado Evolução e desigualdade na educação brasileira Castro estabelece:

Nos países mais desenvolvidos a educação é parte das políticas sociais, compondo o núcleo do sistema de promoção social mediante sua capacidade de ampliar as oportunidades para os indivíduos, além de ser um elemento estratégico para o desenvolvimento econômico. Por isso absorve elevada quantidade de recursos públicos. No Brasil, mais recentemente, ocorreram avanços importantes na ampliação do acesso a todos os níveis e modalidades educacionais, chegando à universalização do acesso ao ensino fundamental. No entanto, ainda é um grave problema a baixa escolaridade média da população e a desigualdade permanente, o que mantém na pauta das discussões a necessidade da universalização da educação básica e a melhoria da qualidade da educação, bem como a eliminação do analfabetismo, com inevitáveis impactos de longo prazo para a área. (CASTRO, 2009, p.674). 
Essas considerações postas pelo autor apresentam os aspectos fundamentais da educação no país. Embora se posicione entre as dez maiores economias do mundo fica patente a não existência de um desenvolvimento social capitaneado pelo sistema educacional. $\mathrm{O}$ ensino superior, tomando-se por referência o estabelecimento de universidades, é uma realização praticamente do início do século passado. O marco foi a criação da Universidade do Rio de Janeiro (1920). Consequentemente, adveio daí um atraso cientifico e tecnológico orgânico ao desenvolvimento de um capitalismo tardio de égide colonial. Com ressalva para "ilhas" de excelências.

No tocante ao ensino superior pode-se aventar este encontrar-se mais ao lado de um processo elitista que um fator de democracia e desenvolvimento humano. Na perspectiva do dualismo a educação pública destinada ao povo dirigiu-se como um instrumento de formação básica de mão de obra de baixa valoração mercadológica e sociocultural. Os/as mais aquinhoados/as seguiram rumo à universidade. Deste modo, passaram a ocupar posições de destaque no processo gerencial da sociedade. Paradoxalmente, o ensino superior de qualidade o foi, e ainda o é, para as camadas de melhor situação socioeconômica e cultural. Ainda que haja distorções internas nesta classificação. Os de menor poder aquisitivo, quando acessam esta classe de universidade, fazem-no na condição de sujeitos classificados com escores menores. (MELO, 2016 a).

Análises concebem que a desigualdade social e sistema educacional são dois elementos que encontram raízes no processo produtivo. Assim, podem ser compreendidas como elementos estruturais da sociedade capitalista. Nessa percepção, o sistema educacional assume um papel crucial na reprodução da alienação e da divisão social do trabalho. Isto porque as escolas têm se configurado como um espaço estratégico de convivência social centrado na reprodução da sociedade capitalista. (LOBO e EUZÉBIOS FILHO, 2005).

Tomadas em um sentido lato as políticas de acesso ao ensino superior surgiram como uma estratégia de ampliação das oportunidades de superação das desigualdades sociais latinoamericanas (CIROLEU, 2009). No Brasil, as análises indicam tais políticas com uma característica distinta conforme os compromissos assumidos pelo poder público. (PEREIRA e SILVA, 2010).

A Constituição Federal de 1988 traz no seu bojo o princípio da educação como um direito público subjetivo e humano. Isto significa que o poder público tem obrigações de realizar políticas para o estabelecimento da educação como um direito social. Cabe ainda destacar a prerrogativa de o sujeito deste direito ter o poder de constranger judicialmente o 
poder público pela não efetivação do mesmo. Contudo, a participação individual e coletiva nessa seara ainda é prática limitada e limitante da democracia.

Nesta linha de raciocínio o poder público brasileiro tem sido ineficaz, historicamente, na oferta plena de políticas públicas como mecanismos de efetividade deste direito. Embora haja discussões no âmbito da "judicialização" e da "jurisidicização" dando conta da existência de limites financeiros. Tais implicações deixa uma sensação de tibieza da ação democrática para a inclusão de diversos sujeitos no alcance de direito de tão cara natureza à realidade social e da pessoa.

O fato é que não há uma correspondência à escala dos que necessitam ser atendidos em seus direitos. Isto devido à dificuldade de alcança-los por outros caminhos. Espera-se que o poder público o faça como é o caso do acesso e permanência ao ensino superior. Fato este demonstrativo da necessidade de maior protagonismo da sociedade civil organizada. Embora complexa esta situação deixe patente o quanto o binômio liberdade-igualdade se posta como utopia necessária no país. (MELO, 2016 b).

\section{AS POLÍticas EDUCACIONAIS PARA ATENDEIMENTO À DIVERISDADE NAS IFES NOS ÚLTIMOS ANOS.}

$\mathrm{Na}$ definição das políticas educacionais compete ao Estado priorizar políticas universalizantes. Estas devem garantir o acesso das classes populares ao conhecimento na perspectiva da diminuição das desigualdades sociais. As políticas públicas necessitam atender às demandas da sociedade civil na luta pelos direitos sociais básicos. Neste universo as políticas educacionais adquirem status de essenciais tanto para os sujeitos quanto para a coletividade. Contudo, mais que tornar os atores sociais competitivos para o mercado de trabalho, torna-se crucial uma política educacional para a cidadania e a democratização da estrutura ocupacional da sociedade. (HÖFLING, 2001).

Os fundamentos republicanos urgem por políticas de caráter universalizante. Contudo, em realidades societais marcadas por diversidades mister se faz atender a particularismos. As democracias modernas encampam o atendimento às minorias. ${ }^{\mathrm{xi}}$ Desse modo, as políticas públicas educacionais com enfoque socialmente inclusivo enfocam a diversidade. Assim, foram criados programas de governo no âmbito federal para possibilitar a ampliação do acesso e permanência no ensino superior. Dentre as finalidades estavam o combate às desigualdades sociais ${ }^{x i i}$ e regionais consorciadas à democratização do acesso e da permanência dos jovens no ensino superior público federal. 
Dentre essas políticas específicas foram criados o Programa de Apoio a Planos de Reestruturação e Expansão das Universidades Federais - REUNI e o Programa Nacional de Assistência Estudantil - PNAES. O REUNI foi criado com o objetivo de ampliar o acesso e permanência na educação superior, no nível de graduação. O PNAES objetiva ampliar as condições de permanência dos/as estudantes do ensino superior pública federal. Consorciadas a esses dois programas vieram as políticas de ação afirmativa.

As políticas de ação afirmativas ${ }^{x i i i}$ para acesso e permanência nas universidades públicas federais, nos últimos anos, configuraram-se como um fator de avanço dos processos de democratização da universidade ${ }^{\mathrm{xiv}}$ e da sociedade. Ainda que estes resultados tenham limites. Porque as políticas de acesso devem apresentar coadjuvantes na dimensão da permanência. Para a efetivação do sucesso no ensino superior as condições para fazê-lo carecem de medidas concretas. Aqui os limites estendem seus tentáculos em parte representativos das universidades públicas federais, com destaque para as de implantação mais recentes. (MELO, 2015)

Um dos fatores limitante da democratização das IFES é a evasão de estudantes. A compreensão da evasão $^{\mathrm{xv}}$ dar-se em três arranjos da seguinte maneira: a) a evasão do curso (abandono): principal causa: a negligência. Esta pode dar-se por não realização da matrícula, a escola e a transferência, mudança de rumo, bloqueio ou eliminação das partes no nível institucional; b) descredenciamento da instituição, que se caracteriza por fechamento da instituição na qual está matriculado o estudante; c) sistema de fechamento, que estabelece o abando definitivo do sistema de educación superior. (ROSA, 2014, p. 247).

A democratização ou processo de expansão das IFES entre 1997 - 2011 registrou: número de jovens entre 18 e 24 anos na educação superior evoluiu de 7,1\% em 1997 para $14,6 \%$ em 2011. Proporção de jovens (18 - 24) integrantes dos $20 \%$ mais pobres da população brasileira, passou de 0,5\% dos alunos nos cursos de graduação em 1997 para 4,2\% em 2011. ${ }^{\text {xvi }}$

A desigualdade socioeconômica permanece enquanto um problema em termos de acesso à educação superior pública: do grupo dos $20 \%$ com maior renda na população brasileira, a proporção de jovens entre 18 e 24 anos na educação superior passou de $22,9 \%$ em 1997 para 47,1\% em 2011. (LÁZARO et al., 2012).

A garantia de vagas na educação superior por recorte étnico-racial, com condições socioeconômicas fragilizadas, com formação escolar e cultural deficitária, por sua deficiência física, direito este sem uma política de permanência não efetiva oportunidade de democratização plena do acesso; significa apenas expansão das condições de acesso à 
RELACult - Revista Latino-Americana de Estudos em Cultura e Sociedade

Revista Latinoamericana de Estudios en Cultura y Sociedad | Latin American Journal of Studies in Culture and Society V. 03, ed. especial, dez., 2017, artigo n ${ }^{\circ}$ 520| relacult.claec.org | e-ISSN: 2525-7870

educação superior (de 0,5 a 4,2\%). Uma política de cotas para o acesso é fundamental para a criação de políticas de permanência na universidade. 


\section{5 À GUISA DE CONCLUSÃO.}

Diante da revisão da literatura e com base em indicadores estatísticos foi possível expor o objeto de estudo diante da problematização realizada. Neste sentido a percepção da educação como um direito público subjetivo tem um alcance limitado quando os mesmo são pretendidos para pessoas situadas na condição de diferente ou minoria.

Embora tenha havido uma diminuição das desigualdades gerais e incremento nas políticas para atendimento a minorias na educação superior a escala a ser alcançada ainda necessita incrementar o foco. Em todo caso, os dados são positivos para os resultados das políticas para ampliação do acesso e da permanência nas IFES. Contudo, essas políticas ainda são avaliadas como de alcance limitado e sem integração entre as mesmas. Nessa dimensão, a efetivação do direito À educação superior por sujeitos marcados por recortes étnicos e culturais carecem de outras ações complementares ao não se restringirem apenas à assistência estudantil. Sobretudo ações de cunho psicopedagógico para acompanhar os estudantes com perfil para evadir-se ou abandonar o curso superior. As buscas pela diminuição das desigualdades sobretudo nos espaços-tempos educacionais precisam estar conectadas com a dimensão da efetividades deste direito público subjetivo.

Assim, é considerado haver-se atingido o objetivo do artigo que foi o de destacar a atenção à diversidade no ensino superior público federal brasileiro com vista à políticas de acesso e permanência dos estudantes com expressões marcadas pela diversidade étnicocultural. 


\section{Referências.}

ANADRADA, Bonifácio J.T. de. Estado. In. Dicionário de políticas públicas / Organizadores: Carmem Lúcia Freitas de Castro, Cynthia Rúbia Braga Gontijo, Antônio Eduardo de Noronha Amabile. Barbacena: EdUEMG, 2012, p. 166 - 168. (Obra Completa).

BAUMAN, Z. Collateral Demage: social inequalities in global age. Cambridge, UK, Polite Press, 2013. (Obra Completa)

BECK, Ulrich ¿Qué es la globalización?: falacias del globalismo, respuestas a la globalización. Barcelona, Paidós, 1998. (Obra Completa)

BOURDIEU, Pierre e PASSERON, Jean C. A Reprodução: Elementos para uma teoria do sistema de ensino. Rio de Janeiro: Editora Vozes, 2014. (Obra completa)

CASTRO, Jorge Abrahão de. Evolução e desigualdade na educação brasileira. Revista Educação e Sociedade, Campinas, vol. 30, n.108, p. 673-697, out. 2009. (Artigo em Periódico Físico)

CASTRO, Mary Garcia. Políticas públicas por identidades e de Ações afirmativas. Acessando gênero e raça, na classe, focalizando juventude. (2004). Disponível em http://www.egov.ufsc.br:8080/portal/sites/default/files/anexos/28334-28345-1-PB.pdf.

(Artigo em Periódico Digital).

CHIROLEU, Adriana. La inclusión en la educación superior como política pública: tres experiencias en América Latina. ISNN: 1681-5653, n.48/5. Organización de Estados Iberoamericanos para la educación, la ciencia y la cultura - OEI. 2009, p. ¿???. Disponível em http://rieoei.org/2740.htm

(Artigo em Periódico Digital).

DURKHEIM, Emile. Educación y Sociología. Buenos Aires, Editorial Shapire, 1973. (Obra Completa).

DUBET, François. As desigualdades multiplicadas. Revista Brasileira de Educação.

Disponível em: $<<$ http://www.scielo.br/scielo.php?pid=S1413-

$24782001000200002 \&$ script=sci_abstract\&tlng=pt $\gg$. Acesso em 12/03/2017. (Artigo em Periódico Digital)

EDGAR, Andrew e SEDGWICK, Peter. Teoria cultural de A a Z: conceitos-chave para entender o mundo contemporâneo. São Paulo: Ed. Contexto, 2003. (Obra Completa).

FELLET, João. 305 etnias e 274 línguas: estudo revela riqueza cultural entre índios no Brasil. BBC BRASIL, 3 de julho de 2016. Disponível em: http://www.bbc.com/portuguese/brasil$36682290>$ >. Acesso em 10/03/2017.

GALEANO, Eduardo. Sangue Latino. Disponível em:

$<<$ https://www.youtube.com/watch?v=NFTr4vVhxzU〉>. Acesso em 20/02/2017. 
GEERTZ, Clinfford. A interpretação das culturas. Rio de Janeiro: Editora Guanabara. 1989. (Obra Completa).

GISI, Maria Lourdes e ENS, Romilda Teodora. Políticas de acesso à educação superior: por que avaliar? Revista Diálogo Educacional, Curitiba, v.15, n.44, p.173-193, jan-abr 2005. Disponível

em:

<<https://periodicos.pucpr.br/index.php/dialogoeducacional/article/view/5092/14706 >>

Acesso em 15/03/2017.

GUZZO, Raquel Souza Lobo e EUZÉBIO FILHO, Antônio. Desigualdade social e sistema educacional brasileiro: a urgência da educação emancipadora. Revista Escritos sobre Educação, v.4, n. 2, Ibirité, p. 02 - 07. Disponível em:

<<http://pepsic.bvsalud.org/scielo.php?script=sci_arttext\&pid=S1677-98432005000200005>

Acesso em 10/03/2017. (Artigo em Periódico Digital).

HAAS, Celia Maria e LINHARES, Milton. Políticas públicas de ações afirmativas para ingresso na educação superiores justifica no Brasil? Revista Brasileira de Estudos Pedagógicos, Brasília, v. 93, n. 235, p.836 - 863, set-dez, 2012. Disponível em:

http://www.scielo.br/scielo.php?pid=S2176-6812012000400015\&script=sci_abstract\&tlng=pt Acesso em 10/03/2017. (Artigo em Periódico Digital).

HÖFLING, Eloísa. Estado e políticas (publicas) sociais. Cadernos Cedes, ano XXI, n ${ }^{\circ}$ 55, novembro/2001, p.30 - 41. Disponível em <<http://www.scielo.br/scielo.php?pid=s0101-

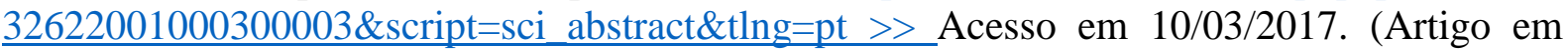
Periódico Digital).

MELO, José Wilson Rodrigues de. Multiculturalismo, diversidade e direitos humanos. In. MELO (Org.) et al. Multiculturalismo, diversidade e direitos humanos. Curitiba: Editora CRV, 2016a, ISBN 978-85-444-0776-9. (Capítulo de Livro).

MELO, José Wilson Rodrigues de. DIVERSIDADE ÉTNICA E DESIGUALDADES SOCIAIS: violência, educação e direitos humanos no Brasil. Anais do VI Seminário Internacional, Direitos Humanos, Violência e Pobreza: a situação de crianças e adolescentes na América Latina: Universidade do Estado Rio de Janeiro, 2016b, $<<$ http://www.proealc.etc.br/VI_SEMINARIO/assets/pdfs/gtvi/Jos\%C3\%A9\%20Wilson\%20 Rodrigues\%20de\%20Melo\%20GT06.pdf >> (Trabalho em Anais de Congresso).

MELO, José Wilson Rodrigues de. Políticas de permanência na universidade. Sucesso, perseverança e abandono: uma breve aproximação à questão no Québec, , Canadá. DESAFIOS: Revista Interdisciplinar da Universidade Federal do Tocantins - V. 1 - n. 02. p. 29-43, jan/jun. 2015. DOI: http://dx.doi.org/10.20873/uft.2359-3652.2015v1n2p29, Disponível em: <<https://sistemas.uft.edu.br/periodicos/index.php/desafios/article/view/952> Acesso em 27/03/2017. (Artigo em periódico digital).

PAULO, Lucila Augusta Lino de. Relações raciais e desigualdade: resistência à política de cotas na universidade. In. MONTEIRO et al. Diversidade étnico-racial e educação superior brasileira: experiência de intervenção. Rio de Janeiro: Quartet Ed. : EDUR : UFRJ, 2008, p. 219 - 239. (Capítulo de Livro). 
PEREIRA, Thiago Ingrassia e SILVA, Luís Fernando Santos Corrêa da. As políticas públicas no ensino superior no /governo Lula: expansão ou democratização? Revista Debates, Porto Alegre, v.4., n.2, p.10 -31, jul-dez 2010. Disponível em http:// www. acesso em 18/03/2017. (Artigo em Periódico Digital).

http://seer.ufrgs.br/index.php/debates/article/view/16316/10573

PNUD. Brasil mantém tendência de crescimento do IDH e reduz pobreza multidimensional, diz Relatório de Desenvolvimento Humano 2015. Disponível em:

$<$ http://www.pnud.org.br/Noticia.aspx?id=4237>>, acesso 15/03/2017.

Portal de Periódicos da CAPES. Disponível em http://www.capes.gov.br. Acesso em 20/03/2017. (Modelo para Sites).

Portal da ERIC. Disponível em http://www.eric.org. Acesso em 18/03/2017. (Modelo para Sites).

https://eric.ed.gov/?q=\%C3\%A9xito\%2C+perseranza+et+deserci\%C3\%B3n+de+la+ense\%C3 \%B1anza+superior

Portal do Google Scholar. Disponível em http:www.google.com/googlescholar. Acesso 15/03/2017. https://scholar.google.com.br/

Portal do Scielo Brasil. Disponível em; $<$ http://www.scielo.org/php/index.php $\gg$. Acesso em 10/03/2017.

QUIJANO, Aníbal. Cordialidad del poder, eurocentrismo y América Latina. Centro de Investigaciones Sociales - CIES, Lima. Disponível em:

$<<$ http://biblioteca.clacso.edu.ar/clacso/sur-sur/20100624103322/12_Quijano.pdf >>Acesso em 15/03/2017. (Artigo em Periódico Digital).

ROBERTSON, Robert. Glocalización: tiempo-espacio y homogeneidad-hetrogeneidad, Zona Abierta, n.92-93, Madrid, 2.000, p.213-241. Disponível em:

<<http://uvirtual.udem.edu.co/file.php/2131/Documentos/Bibliografia/Basica/Tema2/Roberts on_Glocalizacion.pdf $\gg$. Acesso em 10/03/2017.

Ortiz, Renato, "Diversidad cultural y cosmopolitismo”, en Jesús Martín Barbero, Fabio López de la Roche y Jaime Eduardo Jaramillo (editores), Cultura y globalización, CES/ Universidad Nacional de Colombia, Bogotá, 1998. Disponível em:

< http://nuso.org/media/articles/downloads/2680_1.pdf >>. Acesso em 12/03/2017.

ROSA, Chaiane de M. Limites da democratização da educação superior: entraves na permanência e a evasão na Universidade Federal de Goiás. In: Poíesis Pedagógica, Catalão (GO), v. 12, n. 1, p. 240-257, jan/jun. 2014. Disponível em: <<https://revistas.ufg.emnuvens.com.br/poiesis/article/download/31219/16813. >> Acesso em: 26/03/2017.

SAVIANI, Demerval. Política educacional brasileira: limites e perspectivas. Revista de Educação PUC-Campinas, Campinas, n. 24, p. 7-16, junho 2008. Disponível em: $<<$ http://periodicos.puc-campinas.edu.br/seer/index.php/reveducacao/article/view/108/96>> Acesso em 10/03/2-17. 
SILVA, Tadeu Tomaz. Teoria cultural e educação: um vocabulário crítico. Belo Horizonte, Autêntica. 2000. (Obra Completa).

UNIVERSIA BRASIL. Disponível em:

$<$ <http://noticias.universia.com.br/destaque/noticia/2015/10/06/1132040/indice-evasaoensino-superior-brasil-cerca-21-inscreva-seminario.html > . Acesso em 26/03/2017.

WALZER, Michael. Las esferas de la justicia: una defensa del pluralismo y la igualdad. México, D.F.: Fondo de Cultura Económica. 1997. (Obra Completa).

\footnotetext{
i “América Latina es una Patria de la diversidad humana y también que el ejercicio de la solidaridad, cuando se practica de verdad, en el día a día, es también un ejercicio de humildad, que le enseña a reconocerse en los demás ya reconocer la grandeza escondida en las cosas pequeñitas, lo que implica denunciar la falsa grandeza en las cosas grandotas." Eduardo Galeano (Sangue Latino, 2011)
}

ii “ O Estado moderno encontra suas principais raízes no processo político que se desenvolveu na Inglaterra, na França e, em seguida, nos Estados Unidos, espalhando-se por todos os continentes; ora com as roupagens ocidentalizadas que conhecemos, advindas do cenário europeu, ora em formas diversificadas, como no mundo árabe e em regiões longínquas de vida tribal. Portanto, a organização do poder constitui o instrumento dos dirigentes da comunidade para levá-la em busca dos fins de progresso ou da manutenção da ordem."

(ANDRADA, 2012, p.166).

\footnotetext{
iii “A visão segundo a qual padrões de sistemas de moralidade, práticas e crenças fundamentalmente diferentes funcionam em culturas distintas e não podem ser julgados quanto ao seu valor a partir de um ponto de vista exterior a eles". O relativismo cultural, portanto defende que existe uma incompatibilidade fundamental entre os sistemas de diferentes culturas.". (EDGAR e SEDGWICK., 2003: 282-5).
}

\footnotetext{
iv 305 etnias e 274 línguas: estudo revela riqueza cultural no Brasil. "[...] Os dados fazem do Brasil um dos países com maior diversidade sociocultural do planeta. Em comparação, em todo continente europeu, há cerca de 140 línguas autóctones, segundo estudo realizado em 2011 pelo Instituto Histórico Europeu." (FELLET, 2016).
}

\footnotetext{
" Diversidade. "No contexto da chamada "política de identidade", o termo está associado ao movimento do multiculturalismo. Nesta perspectiva, considera-se que a sociedade contemporânea é caracterizada por sua diversidade cultural, isto é, pela coexistência de diferentes e variadas formas (étnicas, raciais, de gênero, sexuais) de manifestação da existência humana, as quais não podem ser hierarquizadas por nenhum critério absoluto ou essencial. Em geral, utiliza-se o termo para advogar uma política de tolerância e respeito entre as diferentes culturas. [...]". (SILVA, T., 2000: 44-5).
} 
vi Geertz define cultura como: um sistema de concepções herdadas, expressas em formas simbólicas por meio das quais os homens comunicam, perpetuam e desenvolvem seu conhecimento e suas atividades em relação à vida. (GEERTZ, 1989, p.103)

vii $O$ termo cultura expressa uma multiplicidade de fatores conjugados de expressões coletivas e individuais. As dimensões da cultura estabelecem os elementos básicos do amálgama social. As culturas compõem as ligas do todo unificado da humanidade. A cultura é o tônico simbólico da compreensão do mundo. $O$ sentido do mundo é enriquecido pela multiplicidade de significados (cosmovisões) a ele atribuídos pelas culturas. A cultura é o substrato da vida humana. A humanidade é o fator de síntese da cultura como patrimônio.

viii Conforme Ulrich Beck: "globalización significa también: “ausencia de" Estado mundial; más concretamente: sociedad mundial "sin Estado mundial" y sin "gobierno mundial. Estamos asistiendo a la difusión de un capitalismo globalmente desorganizado, donde no existe ningún poder hegemónico ni ningún régimen internacional, ya de tipo económico y político." (BECK ,1998, p.32)

\footnotetext{
${ }^{i x}$ A democracia no Brasil é um artefato político precário. No concreto da vida cotidiana dos cidadãos e cidadãs, uns são mais iguais que outros. A construção do imaginário social produziu os não brancos (índios, negros, mulatos, cafuzos, etc.) como seres não livres e incapazes. Por isso, predestinados a uma vida de miséria e de pobreza.
}

× Piérre Bourdieu trata a cultural escolar como violência simbólica (dominação). A escola é entendida como reprodutora dos valores, do imaginário e das condições sociais dominantes do sistema cultural. Ainda segundo o autor, escola é vista como o principal meio utilizado para manter o sistema de domínio social. (BOURDIEU, PASSERON, 2014).

\begin{abstract}
${ }^{x i}$ A compreensão da igualdade pressupõe uma dimensão mais complexa. Walzer estabelece o significado de igualdade complexa nos seguintes termos: (...) En términos formales, la igualdad compleja significa que ningún ciudadano ubicado en una esfera o en relación con un bien social puede ser coartado por ubicarse en otro esfera a un bien distinto. (WALZER, 1997, p.33).
\end{abstract}

\begin{abstract}
xii 0 que se ressalta e se considera um salto para o País é o desencadeamento de um processo em que a elite passe a contar com a contribuição e a participação significativa de cidadãos pertencentes a grupos étnico-raciais injustiçados no contexto da construção da sociedade brasileira, no qual não haverá limitações de acesso ao saber e ao poder, dando efeito à consciência de uma democracia em que a participação da população menos favorecida seja assumida de maneira equilibrada e duradoura. (HAAS e LINHARES, 2012)
\end{abstract}

xiii “ as políticas de ação afirmativas vão além das cotas, porque mesmo se especificas, focalizam necessidades, delimitam programas para recompor defasagens, tocam em diferenças estruturais e culturalmente modeladas 
e têm potencialidade redistributiva ou compensatória e de contribuir para o principio de autonomia. (CASTRO, 2004, p.11)."

xiv No Brasil, a expansão das instituições de educação superior (2003 - 2010), foi da ordem de 27,91\%. Em relação às matrículas, a expansão foi em torno de 40,18\%. O aumento do número de matrículas deu-se na rede privada (aumento de $44,96 \%$ ). A evolução foi de $28,62 \%$ na esfera pública. (ROSA, 2013).

xv Os números da evasão no Ensino Superior - E.S. são da ordem de $22 \%$. Total de estudiantes no E.S. $\rightarrow 7$ millones. Taxa de evasão - T.E. $\rightarrow 1,4$ millones. T.E. nas escolas públicas $\rightarrow 12 \%$;. T.E. nas escolas privadas $\rightarrow 25 \%$. T.E. primeiro semestre $\rightarrow 40$ a 50\%. (Fonte: Universia Brasil; CRUB, 2015).

xvi "Com relação às políticas de acesso à Educação Superior, que se tem configurado no Brasil como um conjunto de programas compensatórios, sem efetivo acompanhamento e avaliação, reiteramos a importância de participação dos grupos beneficiados nos processos avaliativos, haja vista sua valiosa contribuição para o aperfeiçoamento desses processos e para o avanço da democratização do acesso à Educação Superior. (GISI e ENS, 2015)." 